\title{
Hsp90 Inhibitor BlIB028
}

National Cancer Institute

\section{Source}

National Cancer Institute. Hsp90 Inhibitor BlIB028. NCI Thesaurus. Code C78846.

A small-molecule inhibitor of heat shock protein (Hsp) 90 with potential antineoplastic activity. Hsp90 inhibitor BlIB028 blocks the binding of oncogenic client proteins to Hsp90,

which may result in the proteasomal degradation of these proteins and so the inhibition of tumor cell proliferation. Hsp90 is a molecular chaperone that plays a key role in the conformational maturation of oncogenic signaling proteins, such as Her2/Erbb2, Akt, Raf1, Bcr-Abl, and mutated p53, in addition to other molecules involved in cell cycle regulation and immune responses. 